\title{
Short and Medium Chain Fatty Acids and Their Derivatives as a Natural Strategy in the Control of Necrotic Enteritis and Microbial Homeostasis in Broiler Chickens
}

\author{
Luis-Miguel Gomez-Osorio ${ }^{1}$, Veronica Yepes-Medina ${ }^{2}$, Anne Ballou ${ }^{3}$, Manuela Parini ${ }^{4}$ and \\ Roselina Ange/ ${ }^{5 *}$
}

${ }^{1}$ Alura Animal Health and Nutrition, Bogotá, Colombia, ${ }^{2}$ Okuo, Medellín, Colombia, ${ }^{3} / l u m a$ Innovation Labs, Durham, NC, United States, ${ }^{4}$ Silo International, Firenzi, Italy, ${ }^{5}$ Department of Animal and Avian Sciences, University of Maryland, College Park, MD, United States

OPEN ACCESS

Edited by:

Guillermo Tellez,

University of Arkansas, United States

Reviewed by:

Xochitl Hernandez-Velasco, National Autonomous University of

Mexico, Mexico

Roberto Senas Cuesta, University of Arkansas, United States

*Correspondence: Roselina Angel rangel@umd.edu

Specialty section: This article was submitted to Veterinary Infectious Diseases,

a section of the journal

Frontiers in Veterinary Science

Received: 09 September 2021 Accepted: 23 November 2021 Published: 14 December 2021

Citation:

Gomez-Osorio L-M, Yepes-Medina V, Ballou A, Parini M and Angel R (2021) Short and Medium Chain Fatty Acids and Their Derivatives as a Natural

Strategy in the Control of Necrotic Enteritis and Microbial Homeostasis in

Broiler Chickens.

Front. Vet. Sci. 8:773372. doi: 10.3389/fvets.2021.773372
The use of antibiotic growth promoters (AGPs) has historically been the most important prophylactic strategy for the control of Necrotic Enteritis (NE) caused by some Clostridium perfringens toxin types in poultry. During the last five decades, AGPs have also been supplemented in feed to improve body weight gain and feed efficiency as well as to modulate the microbiome (consisting of microbes and their genes both beneficial and potentially harmful) and reduce enteric pathogens, among other benefits. New regulatory requirements and consumer preferences have led to strong interest in natural alternatives to the AGPs for the prevention and control of illnesses caused by enteric pathogens. This interest is not just focused on the direct removal or inhibition of the causative microorganisms but also the improvement of intestinal health and homeostasis using a range of feed additives. A group of promising feed additives is short- and medium-chain fatty acids (SCFA and MCFA, respectively) and their derivatives. The use of SCFA and MCFA, including butyric, caproic, caprylic, capric, and lauric acids, has shown strong effects against NE in broilers both at experimental and commercial levels. These fatty acids also benefit intestinal health integrity and homeostasis. Other effects have also been documented, including increases in intestinal angiogenesis and gene expression of tight junctions. Chemical modifications to improve stability and point of release in the intestine have been shown to improve the efficacy of SCFA and MCFA and their derivatives. The aim of this review is to give an overview of SCFA, MCFA and their derivatives, as an alternative to replace AGPs to control the incidence and severity of NE in poultry.

Keywords: intestinal homeostasis, intestinal health, medium-chain fatty acids, short-chain fatty acids, alpha-monoglycerides, clostridium perfringens, necrotic enteritis, antibiotic growth promoters

\section{INTRODUCTION}

Necrotic enteritis (NE) is a poultry illness caused by toxin-producing strains of Clostridium perfringens $(\mathrm{CP})$ type $\mathrm{A}$, type $\mathrm{C}$ and type $\mathrm{G}(1)$. NE is a pathology of global concern, with important consequences for flock productivity and economic viability (2). The total cost of NE outbreaks worldwide has been estimated to be over 2 billion dollars annually $(3,4)$. NE can present itself 
as a sudden increase in mortality or simply as a subclinical illness (2). CP is a normal inhabitant of the poultry gastrointestinal tract (GIT), although it does not always lead to NE. As an illness, $\mathrm{NE}$ is multifactorial requiring certain predisposing factors for its development, including some not completely known specific diet components (5), poor management leading to stress (6), and the presence of other intestinal pathogens like coccidia (Eimeria spp.) (7), Salmonella (Salmonella Typhimurium) (8) and Avian Pathogenic Escherichia coli (9). For example, components of the diet including b-glucans, mannans, cellulose, and lignin that cannot be digested by the animal can increase the viscosity of the intestinal contents, and can promote the development of NE (10). In addition, high concentrations of diet protein of animal-origin, such as meat and (or) fish meal are associated with a higher risk of NE. The association of these diet ingredients with NE is primarily due to the higher potential for undigested nutrients reaching the lower GIT and becoming a substrate for pathogenic bacteria such as CP and altering the microbiome of the chicken $(11,12)$. Other dietary changes, or increases in stocking density and rapid growth can also cause stress, leading to increased inflammation and immune activity, which can make animals more susceptible to infections like coccidiosis $(6,13,14)$.

Eimeria acervulina and E maxima infection make vulnerable to NE through the induction of local $\mathrm{T}$ cell-mediated inflammatory outcomes that enhance intestinal mucogenesis resulting in increased water, mucus content in fecal material leading to diarrhea (15). A possible relation between coccidialinduced mucogenesis and the NE outbreaks was supported in a pig model of total parenteral nutrition (16). This nutritional model induces small intestinal inflammation with concomitant increase of acidomucin goblet cells and density of mucolytic bacteria such as CP similar to intestinal coccidiosis in the chicken. Mucin, the primary protein component of mucus, is an ideal substrate for the proliferation of $\mathrm{CP}$, as this bacterium has chitinase which is involved in mucine degradation $(17,18)$. On the contrary, mucus may exert a protection, during in vivo conditions, in the ceca against Campylobacter jejuni avoiding the bactericidal effects of medium chain fatty acids (MCFA) in Broilers (19).

Since the 1980s antibiotic growth promoters (AGPs) have been utilized widely in poultry diets to improve performance and feed conversion (20). They have also been utilized to protect animals from the adverse effects of enteric microorganisms (pathogenic and/or opportunistic) (21) as well as to modulate inflammation (22). Reports shows that 24.6 million pounds of antimicrobials are used for non-therapeutic purposes in chickens, cattle, and swine, compared with just 3.0 million pounds used for human medicine (23). Estimations by the pharmaceutical industrysponsored Animal Health Institute are more conservative, suggesting that of 17.8 million pounds of antimicrobials used for animals, only 3.1 million pounds are used nontherapeutically (23). Antibiotics have come under increasing scrutiny by some scientists, consumers, and government regulators due to the potential development of human pathogenic multi-drug-resistant bacteria after prolonged use (24).
The control of NE in particular has been based on the use of AGPs and ionophore anticoccidials. In some regions including the United States and Asia, ionophore anticoccidials and AGPs are used in combination. Therefore, there is an urgent need to develop alternative strategies and interventions that allow for the management of NE from a control and prevention perspective.

\section{ETIOLOGICAL AGENT}

The etiological agent of NE is NetB toxin-producing CP, a Grampositive non-motile rod bacillus that forms subterminal spores. It is a strict anaerobe, although, these bacteria can survive in the presence of oxygen and/or in low superoxide concentration, which makes it an anaerobic aero-tolerant bacillus (25). CP is mainly found in the environment and in the GIT of humans, mammals and birds as a part of normal intestinal microbiota (26). However, under certain predisposing conditions, CP can act as a potent pathogen causing a variety of histotoxic and enteric diseases in humans, pigs, sheep, cows, and birds (27). $\mathrm{CP}$ produces at least 20 different toxins $(28,29)$ and a new classification has been proposed into the 7 toxigenic types A to $\mathrm{G}$ based on the combination of 6 exotoxins known as alpha, beta, epsilon, iota, CPE (Clostridium perfringens enterotoxin) and NetB (toxin related to necrotic enteritis) produced by the bacteria (30). In addition to the above six toxins, CP produces several hydrolytic enzymes and other toxins including lecithinase, hyaluronidase, collagenase, dinases, sialidases (affecting sialic acid in the host cell membrane), amylase, and hemolysin (perfringolisin or PFO or theta toxin) (31).

\section{PATHOGENICITY}

NE occurs when CP proliferates in high numbers in the GIT and produces extracellular toxins, resulting in necrotic lesions which causes increased mortality, rapid loss in performance as well as severe necrosis of the intestinal mucosa $(32,33)$. In recent years it has been suggested that the pore-forming NetB-positive $\mathrm{CP}$ is probably the main cause of NE in poultry (34). In fact, CP NetB-toxin has been reported to induce NE without the presence of alpha-toxin (35). The importance of NetB in NE was demonstrated when a NetB-targeted mutant of a virulent $\mathrm{CP}$ chicken isolate was constructed by homologous recombination and did not cause NE in an experimental chicken model and virulence was restored when the gene was reintroduced into the same strain (36). The cause of tissue damage and cell death appears to be similar to that caused by many other pore-forming toxins in that the pores formed by NetB allow the free flow of ions such as $\mathrm{Na}^{+}, \mathrm{Cl}^{-}$, and $\mathrm{Ca}^{2+}$ which can lead to osmotic cell lysis (37). However, the mechanism of cell death has not been conclusively elucidated for this toxin.

\section{CONTROL OF NE IN BIRDS}

Control strategies that can be utilized to manage NE include reduction of infection pressure of pathogens, boosting of the immune response and nutritional strategies using specific 
feed additives. Pathogen reduction strategies generally involve establishing effective biosecurity at the farm site, use of AGPs, and longer down-time between flocks as well as strict cleaning and disinfection protocols.

AGPs have been used as an effective tool to improve animal performance because they positively modify the GIT microbiota, decreasing bacterial fermentation, reducing the thickness of the GIT wall and suppressing bacterial catabolism (38). All of these mechanisms potentially lead to improved nutrient availability as well as contribute to the health and performance of the bird (20). Thus, dietary AGPs not only improve poultry growth and feed conversion ratio, can but also help control outbreaks of enteric diseases (3).

Prior to the discovery of the NetB toxin, vaccination was focused on toxins that may not have been associated with NE, e.g., $\alpha$-toxin (39). Therefore, the vaccines had only limited efficacy in controlling NE. On the other hand, coccidiosis vaccination has been used to protect birds for the occurrence of NE $(40,41)$, given that coccidiosis is one of the predisposing factors (3). However, most NE experimental models are based on using oral inoculation of coccidia with about 70.000 and 5.000 sporulated oocyst per bird of E. acervulina and E. maxima respectively, in non-vaccinated animals at day 7 of age $(42,43)$. This Eimeria (E. acervulina and E. maxima) vaccination has been shown to cause mucogenesis and intestinal damage favoring the growth of $\mathrm{CP}$ resulting an $\mathrm{NE}$ lesions $(15,44)$. However, protection of birds against $\mathrm{NE}$ was partially achieved by vaccination with recombinant $\mathrm{NetB}$ ( $\mathrm{rNetB}$ ) or other antigen-related or combination vaccines but further research and development is needed if full protection is to be achieved (45).

\section{NATURAL CONTROL ALTERNATIVES}

Nutritional mitigation strategies have been widely used to reduce enteric diseases such as NE, with a focus on intestinal homeostasis (46). Some of the nutritional interventions that have shown potential for improving intestinal health include the inclusion in diets of short chain fatty acids (SCFA) and MCFAand their derivatives, prebiotics, probiotics, essential oils, vaccination, enzymes, and phytobiotics in poultry diets $(1,6,47,48)$.

\section{SHORT AND MEDIUM-CHAIN FATTY ACIDS}

Organic and inorganic acids are widely used in both raw materials and finished animal feeds to inhibit bacterial growth as well as enteric pathogens. The mode of action of these acids is based on the basic principle that undissociated organic acids (non-ionized, more lipophilic) can penetrate the bacterial cell wall triggering an ionization of fatty acids, which results in disruption of the normal physiology of certain types of bacteria (49-51) including an increase in fluidity, solubility, permeability, and instability of the bacterial membrane $(52,53)$. Specifically, an in-vitro study showed that E.coli was negatively affected by the presence of acetate. In a modeling study based on the impact of weak acids (Benzoic, Nitric and Sorbic) on yeast the mechanisms of inhibition of the yeast are defined rapid diffusion of undissociated molecules through the membrane followed by these molecules once inside the cells releasing protons resulting in cytoplasmic acidification and reduced growth. In an in vitro study, 100\% of Pseudomonas aeruginosa in a biofilm was killed by acetic acid (51). During these activities, the detergent properties of the fatty acids play a key role in preventing biofilm assembly (54). After that, the bacteria inner fluid leak into the outside of the cell, inhibiting growth and causing bacterial death (55).It has been proposed that the undissociated fatty acids, once they are inside of the bacteria, an intracellular acidification occurs, which adversely affects their amino acids and enzymes (56, 57). In addition, MCFA inhibit bacterial toxin production and expression of other virulence factors by interfering with signal transduction $(58,59)$. The effect of these acids is both bactericidal (killing) and bacteriostatic (growth-inhibiting) depending on the concentration, synergism among them, and target bacterium $(60,61)$. The acids most commonly used in diet supplementation for the control of microorganisms are formic acid, benzoic acid, citric acid, carboxylic acids (all SCFA) and their salts and as well as some MCFA including Caproic (C6:0), Caprylic (C8:0), Capric (C10:0) and Lauric acid (C12:0) $(62,63)$.

Although important health benefits of SCFA and MCFA have been identified in in-vitro models, direct addition of these compounds in animal feed had been limited due to their pungent odor and unpleasant taste. New products have been developed through the formation of calcium and/or sodium salt with the fatty acids or esterification of these acids prior to addition to feed. Esterification has an important advantage as the esterified SCFA and MCFA escape gastric digestion thus reaching the small intestine where they can exert their effect $(61,64)$. When these acids, in salt or esterified form are fed to animals, positive effects on growth performance, intestinal microbial growth and health status of the animals are seen (65). The potential effect of SCFA and MCFA without any protection would be limited because of prompt absorption and metabolism or both in the gastric area of the intestinal tract.

An important factor for an organic acid to control pathogens in the animal is the $\mathrm{pH}$ of the digesta in different regions of the GIT. For example, in the poultry GIT, the passage of organic acids through the proventriculus is critical because of the effect of $\mathrm{pH}$ on the dissociation of these acids (66). The pKa value of the acid is the $\mathrm{pH}$ at which $50 \%$ of the acid appears in its undissociated form (water-soluble molecule) and 50\% in its dissociated form (fat-soluble molecule). This balance changes depending on the $\mathrm{pH}$ of the medium. The $\mathrm{pKa}$ value determines the capacity of an acid to get close to bacteria, as well as determining whether it is a pH-reducing or antimicrobial acid (Table 1).

MCFA have a higher $\mathrm{pKa}$ value than other organic acids, so they are more effective in controlling microbial growth than in reducing $\mathrm{pH}$. The higher the $\mathrm{pKa}$ value and the smaller the difference between the acid's $\mathrm{pKa}$ and the $\mathrm{pH}$ in specific area of the GIT (proventriculus, gizzard, small intestine, ceca, colon), the more the balance will shift to the undissociated form and the greater the antimicrobial effect (68). SCFA and MCFA will remain mostly undissociated in the acidic environment of the upper gastrointestinal tract (69). Undissociated free fatty acids can 
TABLE 1 | pKa values for different organic acids with potential antimicrobial capacity (67).

\begin{tabular}{llll}
\hline Acid & Classification $^{\mathrm{a}}$ & Chemical name & pKa \\
\hline Acetic & SCFA & Acetic acid & 4.76 \\
Propionic & SCFA & 2-propanoic acid & 4.88 \\
Butyric & SCFA & Butanoic acid & 4.82 \\
Caproic & SCFA & 1-Hexanoic acid & 4.88 \\
Caprylic & MCFA & 1-Octanoic acid & 4.89 \\
Capric & MCFA & Decanoic acid & 4.90 \\
Lauric & MCFA & Dodecanoic acid & 5.30 \\
\hline
\end{tabular}

${ }^{a}$ Classified as SCFA $\leq 6$ carbons; MCFA $\geq 7-12$ carbons.

readily cross the cell membrane of the pathogens and exert their bactericidal activity more easily in the whole GIT and not only in the proximal area (70). Additionally, the efficacy of SCFA and MCFA may be enhanced when supplied in their monoglyceride forms. The reason for this is that these fatty acids are not absorbed in the upper intestine and would not be released as free fatty acids without lipase activity that occurs in the duodenum, and, hence, might have higher bactericidal activity in the distal part of the intestine (i.e. hindgut). Given their molecular structure and supposed undissociated character, monoglycerides of MCFA are assumed to have antibacterial potency which is less $\mathrm{pH}$ dependent when compared to their corresponding free fatty acids (71).

However, some studies have shown no consistent effects of SCFA and MCFA. For example, the supplementation of $400 \mathrm{mg}$ per ton of feed of Lauric acid did not reduce NE occurrence when in a model of co-infection with netB-positive $C P$ and multi-species Eimeria was applied to induce NE (72).

\section{ANTIMICROBIAL ACTIVITY OF SCFA OR MCFA AND THEIR DERIVATIVES (ALFA MONOGLYCERIDES)}

Non-dissociated and non-polar acids pass more efficiently through the liposoluble membrane of the bacteria. Once inside the bacteria, the acid dissociates, releasing hydrogen ions (protons), drastically reducing the intracellular $\mathrm{pH}$ of the microbe. This decrease in $\mathrm{pH}$ causes the bacteria to try and protect itself by expelling those protons which is an energy demanding process (73). If the required expenditure of energy is high, it can lead the death of the bacteria. Concurrently, the newly dissociated acid inside the microbial cell also have antimicrobial activity by interfering with gene transcription and subsequent protein synthesis, which affects the capacity of the bacteria to multiply and its ability to infect the intestinal mucosa $(24,74)$.

In addition to the need to be present in their undissociated form, another characteristic of fatty acids, both in free and salt forms, is their rapid intestinal absorption, which is closely related to their solubility in the watery intestinal content. MCFA and SCFA are quite soluble and as a result tend to diffuse directly into enterocytes, showing little dependence on bile salts or other emulsifying substances (3). This rapid absorption drastically reduces the presence of acids in the intestine, especially in the lower GIT. To increase the presence of these acids in the distal portion of the GIT, high inclusion levels in the diet are required with more than $0.5-1 \%$ diet inclusion often necessary to ensure antimicrobial activity in the lower tract (75). To minimize rapid intestinal absorption in the upper intestine, encapsulation in a hydrogenated lipid matrix $(3,76)$ slows the release of these acids in the GIT. The action of endogenous pancreatic lipases on the lipid-based encapsulation allows for a slow release of the acids contained inside. However, it is difficult to optimize the balance between degradation of the lipid matrix along the small intestine as it will depend, in large part, on levels of lipase secreted by the animal $(77,78)$. The goal is to balance the rate of degradation of the encapsulation matrix such that an effective amount of acid reaches the distal intestine while minimizing the amount of acid remaining to be eliminated in the excreta (79).

$1-\alpha$ monoglycerides (esterified adducts of a fatty acid and a glycerol molecule) can be formed with several organic acid including SCFA and MCFA. The linking of the acid to the glycerol occurs at the first position of a glycerol molecule via an ester bond. The success of alpha-monoglycerides lies in this unique molecular structure. The molecules are $\mathrm{pH}$ independent and less susceptible to enzymatic breakdown, which makes them active in the entire GIT. Research shows that alpha-monoglycerides have a much stronger antimicrobial effect compared to conventional organic acids $(73,80,81)$. The amphipathic monoglycerides form micelles that penetrate the cell membrane and alter membrane permeability (82). This is explained by their mixed character (water and lipid soluble) leading to their entry through the bacterial membrane. SCFA 1- $\alpha$ monoglycerides can penetrate through the aquaglyceroporins in the bacterial wall (Figure 1). These are protein structures that act as channels allowing the entry of glycerol, which is used by the bacteria as an energy source.

MCFA 1- $\alpha$ monoglycerides disrupt the phospholipid membrane of pathogens forming micelles at lower concentrations than MCFAs, which helps to explain why monoglycerides are often more biologically potent than other types of SCFA and MCFA. For some bacteria the longer-chain acids or longer-chain monoglycerides may be more effective (for example, C12 may prove to be more effective than C10 or C8), but with other types of bacteria the situation may be the opposite. (84). For example, the C12 monoglyceride (glycerol monolaurate, abbreviated as GML) has a lower critical micelle concentration (CMC, defined as the concentration of surfactant above which micelles form) value $(60 \mu \mathrm{mol} / \mathrm{L}$ at $\mathrm{pH}$ 7.4) and typically greater potency than both the C12 fatty acid (lauric acid; CMC of $900 \mu \mathrm{mol} / \mathrm{L}$ at $\mathrm{pH} 7.4$ ) and $\mathrm{C} 10$ monoglyceride (glycerol monocaprate; CMC of $600 \mu \mathrm{mol} / \mathrm{L}$ at $\mathrm{pH}$ 7.4) (85). Another important consequence of MCFAs and monoglycerides targeting pathogenic membranes is that it is more difficult for susceptible pathogens to develop resistance to these compounds. It is generally acknowledged that there is a very high barrier for pathogens to develop resistance to fatty acids and monoglycerides $(80,86)$. This antimicrobial activity has been confirmed for different SCFA and MCFA monoglycerides, which are effective against intestinal pathogens 


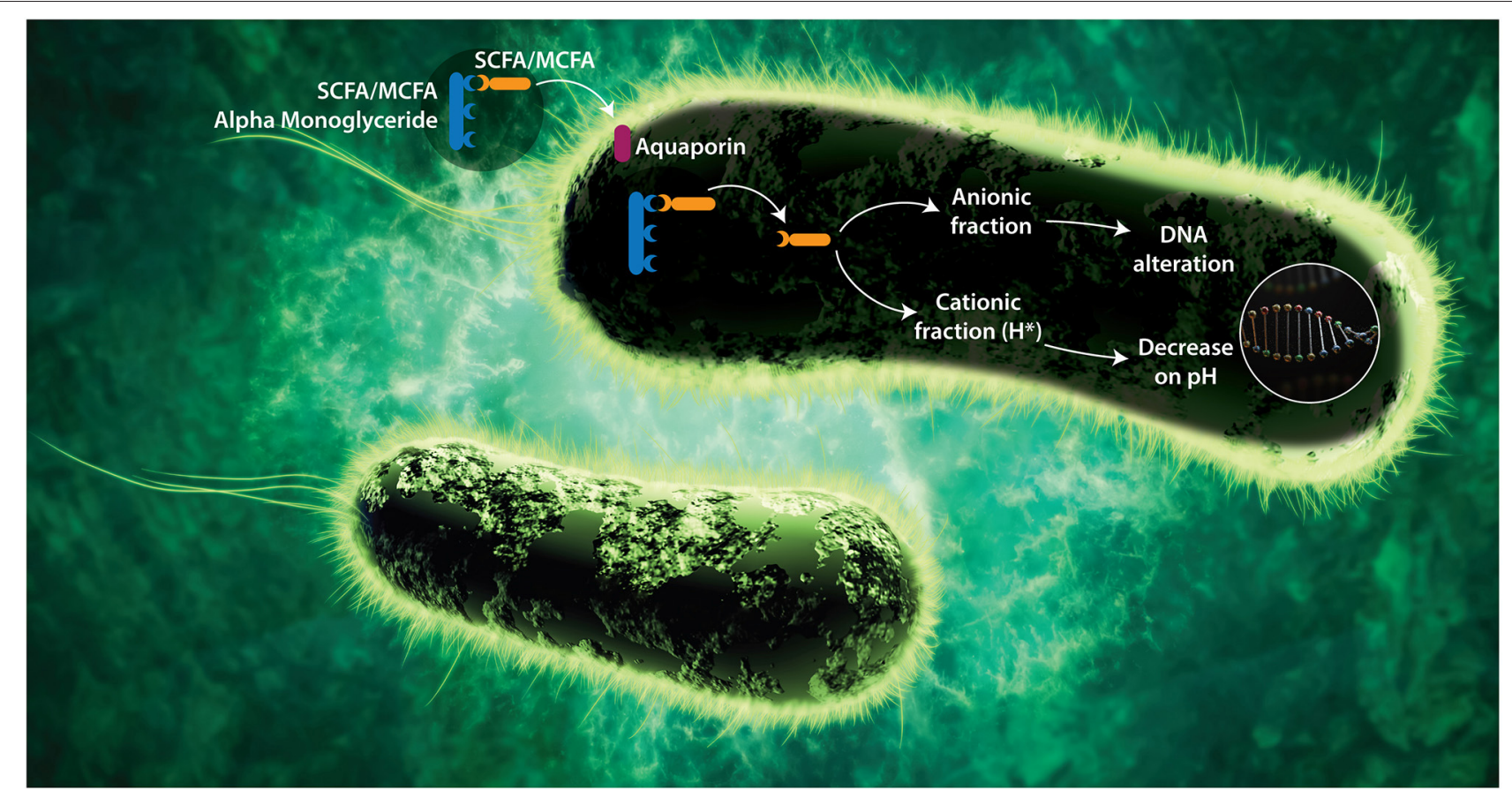

FIGURE 1 | Proposed mode of action of SCFA and MCFA Monoglycerides. Alpha-monoglycerides can pass through the GIT without dissociating (as a by-pass effect) since they are linked to a glycerol. To carry out their antimicrobial functions, FA must penetrate the bacterial membrane and dissociate within the bacteria. Alpha-monoglycerides are absorbed by the bacterium through membrane proteins called aquaporins, which are selective toward glycerol due to its energetic capacity. Once they are inside the bacterium, the FA dissociates from the glycerol likely under the effect of specific enzymes (bacterial lipase), releasing its cationic $(H+)$ and its anionic (A-) fraction (83). As the bacterium does not have a nuclear membrane, the nucleic acids are free in the cytoplasm and the anionic portion of the acid interacts directly with them, affecting the processes of translation, transduction, and replication. Bacterial pathogenesis depends on the expression of virulence factors that are encoded at the DNA, and those depend on transduction and translation mechanisms, therefore there would be a negative impact on the pathogenic capacity and on the expression of resistance mechanism in microorganisms $(58,59,76)$. On the other hand, the cationic fraction ( $\mathrm{H}+)$ of the acid decreases the internal $\mathrm{pH}$ of the bacterium, denaturing proteins and affecting the enzymatic activity. The catabolic activity of the enzymes depends on the $\mathrm{pH}$, therefore, if the $\mathrm{pH}$ decreases, the isoelectric point needed for the catabolic activation is modified and the metabolism of the bacteria decreases, leading to bacteriostasis (73). To counteract the decrease in $\mathrm{pH}$, the bacterium tries to remove the hydrogen ions through membrane protein complexes (ATPases) that lead to significant energy expenditure.

such as Salmonella Typhimurium, E.coli, Campylobacter jejuni, and Clostridium spp $(62,79,86)$. An interesting effect was shown with the inclusion of $3 \mathrm{mg} / \mathrm{kg}$ of Caproic acid to the feed of Broiler Chickens which suppress the expression of Salmonella pathogenic genes required for invasion of host cells as well as decreasing the amount of bacteria (87). It was also reported that the application of an emulsion mixture of MCFA (Caproic, Caprylic, Capric and Lauric acids) in drinking water at $0.4 \% \mathrm{vol} / \mathrm{vol}$ decreased the susceptibility to colonization and prevented Campylobacter jejuni survival (88).

Minimum inhibitory concentrations (MICs) are defined as the lowest concentration of an antimicrobial that will inhibit the visible growth of a microorganism after overnight incubation (89) and are considered the "gold standard" for determining the susceptibility of bacteria to the antimicrobials and recently has been used to test natural compounds as replacement for antibiotics. When evaluating the antimicrobial effect of various organic acids in vitro, MCFA showed lower minimum inhibitory concentrations (MIC) compared to other fatty acids such as butyric acid (Table 1). In an experimental in vitro model of NE in broilers, lauric acid, butyric acid and essential oils (eucalyptus, clove with its active ingredient eugenol and components of essential oils such as thymol, carvacrol and cinnamaldehyde) were tested individually, it was shown that lauric acid had antimicrobial activity against CP with a MIC of $0.063 \mathrm{mg} / \mathrm{mL}$ compared with butyric acid of $6.88 \mathrm{mg} / \mathrm{mL}$ (1).

When tested in vivo in Broiler Chickens, killing or inhibition of CP was associated with the prevention of intestinal injuries (1). These researchers also showed that butyrate did not inhibit CP, although butyrate has been reported to be a stimulant of intestinal villus growth (90). Butyrate is a preferred energy-providing substrate over glucose and glutamine for colonic epithelial cells and may account for approximately $70 \%$ of the total energy consumption of the colonocytes (91). Other documented effects of butyrate (in a Caco- 2 cell culture model) are increase cell proliferation in the small and large intestine $(92,93)$, and enhance piglet intestinal barrier associated with its role in facilitating tight junction assembly (90). Overall, the combination of butyric acid, MCFA, and essential oils reduces the incidence of gross lesions and promotes intestinal mucosal integrity in the control of NE.

However, research has shown better results using a mix of organic acids (consisting of Formic, Lactic, Propionic, Butyric, 
TABLE 2 | MIC in mg/L (+SD) of various organic acids and their derivatives against Clostridium perfringens strain ATCC strain 12,915 (control strain recommended by the British Society for Antimicrobial Chemotherapy-BSAC) (62)

\begin{tabular}{lc}
\hline Compound & MIC in $\mathbf{~ g} / \mathbf{L}( \pm \mathbf{S D})$ against Clostridium perfringens* \\
\hline Butyric acid & $1,200( \pm 400)$ \\
Valeric acid & $1,300( \pm 700)$ \\
Sodium Formate & $18,800( \pm 7,100)$ \\
Monopropionin & $11,300( \pm 6,400)$ \\
Monobutyrin & $2,600( \pm 1,300)$ \\
Monovalerin & $3,100( \pm 1,200)$ \\
Monolaurin & $300( \pm 400)$ \\
\hline
\end{tabular}

MIC, Minimum inhibitory concentration. * Clostridium perfringens ATCC 12,915.

Acetic, Citric, Sorbic and Benzoic acids) used in comparison with MCFA blends included in feed at a $0.2 \%$. This study pointed out that organic acids improved the ceca environment, beneficial microorganism (numbers and species variety of probiotic bacteria in the ceca) more so than MCFA and that feed to gain ratio over the whole production cycle (1 to $42 \mathrm{~d}$ of age) was better in Broilers fed the organic acids as compared to those fed the MCFA (94).

The antimicrobial activity of organic acids and their derivatives against several gram-negative and gram-positive bacteria including CP were reported in an in vitro trial (62). The MICs in $\mathrm{mg} / \mathrm{L}( \pm \mathrm{SD})$ of the organic acids and their derivatives against CP strain ATCC 12,915 are shown in Table 2 for butyric acid, valeric acid, and monobutyrin and monolaurin against $\mathrm{CP}$ (62). The results suggested that valeric and butyric acid have similar antimicrobial activity against gram-negative and grampositive bacteria. The mode of action of these acids is based on their ability to penetrate the bacterial cell membrane and acidify the cell cytoplasm and thus inhibiting bacterial growth. In vitro conditions may be affected by buffering capacity of the solution that contains the free acids (Butyric and Valeric). The solution used for MIC determination in this study (41) had a low $\mathrm{pH}$ and, in those conditions, the acids perform well.

Some combinations of encapsulated organic acids blended with essential oils were assessed to mitigate NE, including Malic, Fumaric, Capric, Caprylic, Caproic and Lauric acid as well as calcium Butyrate, as sources of SCFA and MCFA in Broiler Chickens. In a study, recycling litter was used as a challenge, with this litter selected from a commercial poultry flock there was clinical NE outbreaks was diagnosed (95). These researchers reported that the supplementation with calcium Butyrate plus essential oils (Cinnamaldehyde, Carvacrol and Thymol (8:1:1 parts of each) as well as a blend of organic acids (Fumaric and Citric acid) and MCFA (Capric, Caprylic, Caproic and Lauric acid) plus calcium Butyrate ameliorated the negative effects of a NE challenge on performance and mortality (95). These researchers found a dose was important as high doses were detrimental to animal performance.

The efficacy of SCFA in combination with high doses of MCFA has been shown to be more effective in improving performance parameters in a NE challenge model in Broiler Chickens.
(96). Moreover, a monoglyceride blend of MCFA (Butyric, Caprylic and Capric acid) enhanced the overall feed efficiency of birds compared with the non-supplemented group in a phase dependent effect. Higher doses (0.2\%) of monoglyceride MCFA supplementation appear to be beneficial in grower phase $(\mathrm{d}$ $10-24)$ and low doses $(0.075 \%)$ improved the performance in the finisher phase (d 24-35) (96). In another study, a blend of Monoglyceride of MCFA (Butyric, Caprylic, and Capric acids) and buffered Formic acid, used at 0.03 to $0.05 \%$ inclusion rate in the diet, showed the potential to improve intestinal health and reduce the mortality caused by $\mathrm{NE}$ induced by inoculation of a blend of field isolated Eimerias (E.acervulina, E.maxima and E.brunetti) followed by a CP challenge (97).

Other researchers have evaluated individual MCFA monoglycerides. Valeric acid (C5) was tested in a NE challenge trial (Coccidia vaccine follow by CP) (98). They demonstrated that low doses of Valeric acid (0.5 and 1.5\%) improved performance but did not decrease NE lesions. They also showed that Valeric acid positively affected the morphology of the intestinal mucosa (98). The effects of Lauric acid, a MCFA, on induced NE was not effective in reducing the incidence and severity of NE (72). This contrasts with a previous study showing that the same inclusion of Lauric acid decreased NE incidence (from 50 to $25 \%$ ) compared with an uninfected untreated group (1).

\section{ROLE OF THE MICROBIOTA IN CONTROL OF NE}

As mentioned elsewhere in this review, other microbes can have an important role in an NE mitigation and prevention strategy. The acquisition of a diverse, stable microbiome during development is very important in resisting endemic challenges such as NE. The development of a healthy microbiome can be aided in many ways through nutrition, water quality, and other management choices. While the feed can be a source of microbes for the GIT, many bacteria found in common feed substrates are not ideally suited to long term survival in the GIT. Bacteria that aid in the development of a healthy microbiome can be supplemented with probiotic feed additives. The variety of probiotics available in the poultry industry is too large to cover in this review; however, some have shown promising benefits in the reduction of the incidence and severity of NE $(99,100)$. In addition to supplementation through the diet, the environment can be an important factor in microbiome-mediated resistance to NE. Studies evaluating the recycling or reuse of litter in poultry barns have demonstrated lower levels of toxin-producing CP in the ileum of broilers on used litter vs. fresh $(101,102)$, suggesting the contribution that previous flocks can have in helping in the development of a balanced and healthy microbiota in chicks.

The extent to which other GIT microbes affect or are affected by NE is still under investigation. It has been reported that even in the absence of clinical NE, the addition of predisposing factors of NE such as high levels of fish meal and non starch polysaccharides can reduce the levels of several butyrate and lactate producing bacteria (103). These bacteria include Lactobacillus johnsonii, 
Ruminococcaceae, and Candidatus savagella, all of which have previously been associated with GIT homeostasis and better animal health $(104,105)$. It is difficult to demonstrate a causal relationship between these microbiome changes and susceptibility to $\mathrm{CP}$ overgrowth and NE, but the fact that these and related species normally make up a significant portion of the ileal and/or cecal microbial populations suggests that in healthy animals, they play an important role in maintaining balance between normal GIT microbial constituents $(11,106)$.

The impact other microbes have on the incidence of $\mathrm{CP}$ can be driven by several mechanisms; competitive exclusion (the competition for a particular resource or niche in the GIT), release of bacteriocins, and possibly even the interruption of $\mathrm{CP}$ quorum sensing in pathogenic populations. From in vitro studies into the quorum sensing mechanisms used by NetB-producing CP there is a strong suggestion that this is an important step in the pathogenesis of CP in poultry (107). Our understanding of quorum sensing in complex communities such as the GIT microbiome is in its infancy. Researchers have reported several instances of interspecies cross-talk and interference in quorum sensing $(108,109)$.

\section{SCFA, MCFA AND THE MICROBIOME}

Though the GIT microbiome may help regulate $\mathrm{CP}$ pathogenesis in several ways, secretion of metabolites such as butyrate and other SCFA are likely an important part of these mechanisms. Many common GIT bacteria ferment dietary fiber and even protein and produce SCFA (110). Firmicutes such as Faecalibacterium, Clostridium, and Ruminococcaceae are the principal producers of SCFA in the hindgut, and Akkermansia and Bifidobacterium also produce lactate and limited quantities of butyrate (111). Cross feeding is an important factor in the production of SCFA in the GIT, and one of many ways in which changes in bacterial composition can affect the host. Certain metabolites of bacterial fermentation are substrates for other bacteria to ferment, altering the composition of the GIT metabolome in important ways. For example, acetate and lactate produced by Bifidobacterium and Bacteroidetes can be consumed by butyrate-producing microbes such as Faecalibacterium and Roseburia (112).

Additionally, the GIT contains a group of g-protein coupled receptors called free fatty acid receptors, capable of reacting to SCFA. This results in a variety of different responses affecting various host systems, including the secretion of GIT hormones such as peptide YY (PYY) and glucagon-like peptide 1 (GLP1) (113). These molecules are important for the proper regulation of insulin, satiety, and appetite stimulation. Additional downstream impacts of SCFA-free fatty acid receptor (FFAR) signals include various inflammatory and immune responses (114).

SCFA, specifically butyrate, and MCFA do not typically exert strong effects on the microbial composition of the normal chicken GIT (115). However, in situations in which the GIT microbial homeostasis is challenged or susceptible to change, i.e. during periods of stress or pathogen challenge, supplementation with butyrate seems to reduce the impact of the challenge on the microbiota $(116,117)$. This suggests that SCFA can exert a homeostatic effect in the GIT microbial population. This is an important part of minimizing intestinal pathogens, as stress-related dysbiosis makes the normally resistant microbial community more susceptible to pathogenesis from normal constituents such as CP. Interestingly, supplementation with butyrate can decrease some butyrate-producing species in the chicken cecum. The authors speculate that this could be a feedback mechanism in response to the increased sodium butyrate coming into the GIT from the diet (117). This supports an increasingly recognized facet of the microbiome, a relentless movement toward stability and homeostasis. This complicated community is comprised of hundreds of individual members, each acting in conjunction with other species, the digesta (substrates) and the host to achieve a balance that allows for stable growth and colonization.

Work on MCFA and the microbiota lags considerably behind SCFA, for a few reasons. Though MCFA are nutritionally important and interact with the host in some of the same ways as SCFA, they are not products of microbial fermentation, but are in commercial diets that contain palm kernel, coconut or milk meals or fats. While SCFA, particularly butyrate, are major energy sources for enterocytes and microbes alike, MCFA are primarily metabolized by the host, in the liver (118).

In the last 25 years, the approach to research and ultimately solutions to production problems has had a reductionist approach focusing on understanding parts of the system rather than integrating parts with the whole. That is, looking at small parts of the problem disregarding in most cases the animal as a whole and as a superorganism. Recently, we have been seeing more and more insights into the whole animal universe with numerous components that interact and are the essence of whole animal health. We are just beginning this incredible journey into understanding, from a holistic standpoint, how the environment, feed, digesta, microbiome, and host interact at every turn. A new nascent knowledge on the interaction between the microbial community in the GIT and the cells of immune system affecting whole parts of the body is emerging based on the assumption that intestinal microbes may shape the course of inflammatory illnesses such as autoimmune human diseases like Crohn's disease and Multiple Sclerosis (119). However, outside influences or runaway growth of a few members can upset this balance, the pressure of other community members works constantly to return the community to a balance that favors as many members as possible, rather than a few opportunistic species. The question that arises is if the microbiome differs because animals that are sick or is it different because it causes disease? (120). More mechanistic studies instead of only correlational studies are needed to understand this relationship.

\section{CONCLUSIONS}

Enteric diseases, especially NE, are a major concern in the poultry industry due to production losses, increased mortality, reduced bird welfare and increased risk of contamination of poultry products intended for human consumption. Additionally, public 
concern about the threat of antibiotic-resistant pathogens has forced the poultry industry to consider alternatives to antibioticbased prevention of NE. Strategies to control NE in the absence of AGPs have focused on nutrition and biosecurity. Some promising alternatives include organic acids, SCFA, MCFA and their derivatives, probiotics, prebiotics, enzymes, plant extracts, bacteriophages, and vaccination.

The use of SCFA and MCFA in the form of alpha monoglycerides as an alternative for the control of NE has shown important results in the improvement of intestinal health and therefore in the prevention of the proliferation of pathogenic $C P$ and the release of its toxins which generate strong damage in

\section{REFERENCES}

1. Timbermont L, Lanckriet A, Dewulf J, Nollet N, Schwarzer K, Ducatelle $\mathrm{R}$, et al. Control of Clostridium perfringens -induced necrotic enteritis in broilers by target-released butyric acid, fatty acids and essential oils. Avian Pathol. (2010) 39:117-21. doi: 10.1080/03079451003610586

2. Hofacre CL, Smith JA, Mathis GF. An optimist's view on limiting necrotic enteritis and maintaining broiler gut health and performance in today's marketing, food safety, and regulatory climate. Poult Sci. (2018) 97:192933. doi: $10.3382 / \mathrm{ps} /$ pey082

3. M'Sadeq SA, Wu S, Swick RA, Choct M. Towards the control of necrotic enteritis in broiler chickens with in-feed antibiotics phasing-out worldwide. Anim Nutr. (2015) 1:1-11. doi: 10.1016/j.aninu.2015.02.004

4. Skinner JT, Bauer S, Young V, Pauling G, Wilson J, Skinner JT, et al. An economic analysis of the impact of subclinical (mild) necrotic enteritis in broiler chickens an economic analysis of the impact of subclinical (mild) necrotic enteritis in broiler chickens. (2010) 54:123740. doi: 10.1637/9399-052110-Reg.1

5. Riddell C, Kong XM. The influence of diet on necrotic enteritis in broiler chickens. Avian Dis. (1992) 36:499-503. doi: 10.2307/1591740

6. Tsiouris V. Poultry management: a useful tool for the control of necrotic enteritis in poultry. Avian Pathol. (2016) 45:3235. doi: 10.1080/03079457.2016.1154502

7. Williams RB. Intercurrent coccidiosis and necrotic enteritis of chickens: rational, integrated disease management by maintenance of gut integrity. Avian Pathol. (2005) 34:159-80. doi: 10.1080/03079450500112195

8. Shivaramaiah S, Wolfenden RE, Barta JR, Morgan MJ, Wolfenden AD, Hargis BM, et al. The role of an early Salmonella Typhimurium infection as a predisposing factor for necrotic enteritis in a laboratory challenge model. Avian Dis. (2011) 55:319-23. doi: 10.1637/9604-112910-ResNote.1

9. Fancher CA, Zhang L, Kiess AS, Adhikari PA, Dinh TTN, Sukumaran AT. Avian pathogenic Escherichia coli and clostridium perfringens: challenges in no antibiotics ever broiler production and potential solutions. Microorganisms. (2020) 8:1-27. doi: 10.3390/microorganisms 8101533

10. Moore RJ. Necrotic enteritis predisposing factors in broiler chickens. Avian Pathol. (2016) 45:275-81. doi: 10.1080/03079457.2016.1150587

11. Wu SB, Stanley D, Rodgers N, Swick RA, Moore RJ. Two necrotic enteritis predisposing factors, dietary fishmeal and Eimeria infection, induce large changes in the caecal microbiota of broiler chickens. Vet Microbiol. (2014) 169:188-97. doi: 10.1016/j.vetmic.2014.01.007

12. Rodgers NJ, Swick RA, Geier MS, Moore RJ, Choct M, Wu SB. A multifactorial analysis of the extent to which eimeria and fishmeal predispose broiler chickens to necrotic enteritis. Avian Dis. (2015) 59:3845. doi: 10.1637/10774-011614-Reg.1

13. Dierick E, Hirvonen OP, Haesebrouck F, Ducatelle R, Van Immerseel F, Goossens E. Rapid growth predisposes broilers to necrotic enteritis. Avian Pathol. (2019) 48:416-22. doi: 10.1080/03079457.2019.161 4147

14. Tsiouris V, Georgopoulou I, Batzios C, Pappaioannou N, Ducatelle R, Fortomaris P. High stocking density as a predisposing factor the intestinal epithelium. Although the full mechanism of action of SCFA and MCFA is not well-known, broad-spectrum activity has been demonstrated against gram positive and gram-negative bacteria such as Salmonella, Campylobacter, and Clostridium spp, making them a viable solution to reduce the use of AGPs. They also have synergistic effects when used together and can thus reduce the magnitude and duration of treatments.

\section{AUTHOR CONTRIBUTIONS}

All authors listed have made a substantial, direct, and intellectual contribution to the work and approved it for publication. for necrotic enteritis in broiler chicks. Avian Pathol. (2015) 44:5966. doi: 10.1080/03079457.2014.1000820

15. Collier CT, Hofacre CL, Payne AM, Anderson DB, Kaiser P, Mackie RI, et al. Coccidia-induced mucogenesis promotes the onset of necrotic enteritis by supporting Clostridium perfringens growth. Vet Immunol Immunopathol. (2008) 122:104-15. doi: 10.1016/j.vetimm.2007.10.014

16. Deplancke B, Vidal O, Ganessunker D, Donovan SM, Mackie RI, Gaskins HR. Selective growth of mucolytic bacteria including Clostridium perfringens in a neonatal piglet model of total parenteral nutrition. Am J Clin Nutr. (2002) 76:1117-25. doi: 10.1093/ajcn/76.5.1117

17. Nakjang S, Ndeh DA, Wipat A, Bolam DN, Hirt RP. A novel extracellular metallopeptidase domain shared by animal HostAssociated mutualistic and pathogenic microbes. PLoS One. (2012) 7:287. doi: 10.1371/journal.pone.0030287

18. Prescott JF, Parreira VR, Mehdizadeh Gohari I, Lepp D, Gong J. The pathogenesis of necrotic enteritis in chickens: what we know and what we need to know: a review. Avian Pathol. (2016) 45:28894. doi: 10.1080/03079457.2016.1139688

19. Hermans D, Martel A, van Deun K, Verlinden M, van Immerseel F, Garmyn A, et al. Intestinal mucus protects Campylobacter jejuni in the ceca of colonized broiler chickens against the bactericidal effects of medium-chain fatty acids. Poult Sci. (2010) 89:1144-55. doi: 10.3382/ps.2010-00717

20. Miles RD, Butcher GD, Henry PR, Littell RC. Effect of antibiotic growth promoters on broiler performance, intestinal growth parameters, and quantitative morphology. Poult Sci. [2006] 85:476-85. doi: 10.1093/ps/85.3.476

21. Costa MC, Bessegatto JA, Alfieri AA, Weese JS, Filho JAB, Oba A. Different antibiotic growth promoters induce specific changes in the cecal microbiota membership of broiler chicken. PLoS ONE. (2017) 12:1171642. doi: 10.1371/journal.pone.0171642

22. Butaye P, Devriese LA, Haesebrouck F. Antimicrobial growth promoters used in animal feed: Effects of less well known antibiotics on gram-positive bacteria. Clin Microbiol Rev. (2003) 16:175-88. doi: 10.1128/CMR.16.2.175-188.2003

23. Landers TF, Cohen B, Wittum TE, Larson EL. A review of antibiotic use in food animals: Perspective, policy, and potential. Public Health Rep. (2012) 127:4-22. doi: 10.1177/003335491212700103

24. Dahiya JP, Wilkie DC, Van Kessel AG, Drew MD. Potential strategies for controlling necrotic enteritis in broiler chickens in post-antibiotic era. Anim Feed Sci Technol. (2006) 129:60-88. doi: 10.1016/j.anifeedsci.2005.12.003

25. Kiu R, Hall LJ. An update on the human and animal enteric pathogen Clostridium perfringens. Emerg Microbes Infect. (2018) 7:1-5. doi: 10.1038/s41426-018-0144-8

26. Villagrán De la Mora Z, Macías-Rodríguez ME, Arratia-Quijada J, Gonzalez-Torres YS, Nuño K, Villarruel-López A. Clostridium perfringens as foodborne pathogen in broiler production: Pathophysiology and potential strategies for controlling necrotic enteritis. Animals. (2020) 10:128. doi: 10.3390/ani10091718

27. Wade B, Keyburn AL, Haring V, Ford M, Rood JI, Moore RJ. The adherent abilities of Clostridium perfringens strains are critical for the 
pathogenesis of avian necrotic enteritis. Vet Microbiol. (2016) 197:5361. doi: 10.1016/j.vetmic.2016.10.028

28. Rood JI, Adams V, Lacey J, Lyras D, McClane BA, Melville SB, et al. Expansion of the clostridium perfringens toxin-based typing scheme. Anaerobe. (2018) 53:5-10. doi: 10.1016/j.anaerobe.2018.04.011

29. Uzal FA, Freedman JC, Shrestha A, Theoret JR, Garcia J, Awad MM, et al. Towards an understanding of the role of clostridium perfringens toxins in human and animal disease. Future Microbiol. (2014) 9:36177. doi: $10.2217 / \mathrm{fmb} .13 .168$

30. Boulianne M, Uzal FA, Opengart K. "Clostridial diseases," In: Disease of Poultry 14th, 966-994.

31. Bhunia AK. Clostridium botulinum, Clostridium perfringens, Clostridium difficile. Foodborne Microbial Pathogens. 12:20928. doi: 10.1007/978-1-4939-7349-1_12

32. Latorre JD, Adhikari B, Park SH, Teague KD, Graham LE, Mahaffey BD, et al. Evaluation of the epithelial barrier function and ileal microbiome in an established necrotic enteritis challenge model in broiler chickens. Front Vet Sci. (2018) 5:1-11. doi: 10.3389/fvets.2018.00199

33. Timbermont L, Haesebrouck F, Ducatelle R, Van Immerseel F. Necrotic enteritis in broilers: An updated review on the pathogenesis. Avian Pathol. (2011) 40:341-7. doi: 10.1080/03079457.2011.590967

34. Rood JI, Keyburn AL, Moore RJ. NetB and necrotic enteritis: the hole movable story. Avian Pathol. (2016) 45:295301. doi: 10.1080/03079457.2016.1158781

35. Keyburn AL, Boyce JD, Vaz P, Bannam TL, Ford ME, Parker D, et al. NetB, a new toxin that is associated with avian necrotic enteritis caused by Clostridium perfringens. PLoS Pathog. (2008) 4:e26. doi: 10.1371/journal.ppat.0040026

36. Keyburn AL, Yan XX, Bannam TL, Van Immerseel F, Rood JI, Moore RJ. Association between avian necrotic enteritis and Clostridium perfringens strains expressing NetB toxin. Vet Res. (2010) $4 \mathbf{1}$ :69. doi: 10.1051/vetres/2009069

37. Navarro MA, McClane BA, Uzal FA. Mechanisms of action and cell death associated with Clostridium perfringens toxins. Toxins (Basel). (2018) 10:121. doi: 10.3390/toxins 10050212

38. Broom LJ. Gut barrier function: effects of (antibiotic) growth promoters on key barrier components and associations with growth performance. Poult Sci. (2018) 97:1572-8. doi: 10.3382/ps/pey021

39. Mot D, Timbermont L, Haesebrouck F, Ducatelle R, Van Immerseel F. Progress and problems in vaccination against necrotic enteritis in broiler chickens. Avian Pathol. (2014) 43:290-300. doi: 10.1080/03079457.2014.939942

40. Williams RB, Marshall RN, La Ragione RM, Catchpole J. A new method for the experimental production of necrotic enteritis and its use for studies on the relationships between necrotic enteritis, coccidiosis and anticoccidial vaccination of chickens. Parasitol Res. (2003) 90:1926. doi: 10.1007/s00436-002-0803-4

41. Tsiouris V, Georgopoulou I, Batzios C, Pappaioannou N, Diakou A, Petridou E, et al. The role of an attenuated anticoccidial vaccine on the intestinal ecosystem and on the pathogenesis of experimental necrotic enteritis in broiler chickens. Avian Pathol. (2013) 42:163-70. doi: 10.1080/03079457.2013. 776161

42. Jackson ME, Anderson DM, Hsiao HY, Mathis GF, Fodge DW. Beneficial effect of $\beta$-mannanase feed enzyme on performance of chicks challenged with Eimeria sp. and Clostridium perfringens. Avian Dis. (2003) 47:75963. doi: $10.1637 / 7024$

43. Hofacre CL, Beacorn T, Collett S, Mathis G. Using competitive exclusion, mannan-oligosaccharide and other intestinal products to control necrotic enteritis. J Appl Poult Res. (2003) 12:60-4. doi: 10.1093/japr/12.1.60

44. Nicholds JF, McQuain C, Hofacre CL, Mathis GF, Fuller AL, Telg BE, et al. The effect of different species of eimeria with clostridium perfringens on performance parameters and induction of clinical necrotic enteritis in broiler chickens. Avian Dis. (2020) 65:132-7. doi: 10.1637/aviandiseases-D-20-0 0106

45. Keyburn AL, Portela RW, Ford ME, Bannam TL, Yan XX, Rood JI, et al. Vaccination with recombinant NetB toxin partially protects broiler chickens from necrotic enteritis. Vet Res. (2013) 44:1-8. doi: 10.1186/1297-9716-44-54
46. Adhikari P, Kiess A, Adhikari R, Jha R. An approach to alternative strategies to control avian coccidiosis and necrotic enteritis. J Appl Poult Res. (2020) 29:515-34. doi: 10.1016/j.japr.2019.11.005

47. Caly DL, D’Inca R, Auclair E, Drider D. Alternatives to antibiotics to prevent necrotic enteritis in broiler chickens: a microbiologist's perspective. Front Microbiol. (2015) 6:1-12. doi: 10.3389/fmicb.2015.01336

48. Fowler J, Kakani R, Haq A, Byrd JA, Bailey CA. Growth promoting effects of prebiotic yeast cell wall products in starter broilers under an immune stress and clostridium perfringens challenge. J Appl Poult Res. (2015) 24:6672. doi: $10.3382 / \mathrm{japr} / \mathrm{pfv} 010$

49. Roe AJ, McLaggan D, Davidson I, O'Byrne C, Booth IR. Perturbation of anion balance during inhibition of growth of Escherichia coli by weak acids. J Bacteriol. (1998) 180:767-72. doi: 10.1128/JB.180.4.767-772.1998

50. Lambert RJ, Stratford M. Weak-acid preservatives: modelling microbial inhibition and response. J Appl Microbiol. (1999) 86:157-64. doi: 10.1046/j.1365-2672.1999.00646.x

51. Kundukad B, Schussman M, Yang K, Seviour T, Yang L, Rice SA, et al. Mechanistic action of weak acid drugs on biofilms. Sci Rep. (2017) 7:4783. doi: 10.1038/s41598-017-05178-3

52. Bergsson G, Arnfinnsson J, Karlsson SM, Steingrímsson Ó, Thormar H. In vitro inactivation of chlamydia trachomatis by fatty acids and monoglycerides. Antimicrob Agents Chemother. (1998) 42:2290-2294. doi: 10.1128/AAC.42.9.2290

53. Bergsson G, Steingrímsson Ó, Thormar H. In vitro susceptibilities of Neisseria gonorrhoeae to fatty acids and monoglycerides. Antimicrob Agents Chemother. (1999) 43:2790-2. doi: 10.1128/AAC.43.11.2790

54. Schlievert PM, Peterson ML. Glycerol monolaurate antibacterial activity in broth and biofilm cultures. PLoS ONE. (2012) 7:40350. doi: 10.1371/journal.pone. 0040350

55. Desbois AP, Smith VJ. Antibacterial free fatty acids: activities, mechanisms of action and biotechnological potential. Appl Microbiol Biotechnol. (2010) 85:1629-42. doi: 10.1007/s00253-009-2355-3

56. Viegas C, Sa-Correia I. Activation of plasma membrane ATPase of Saccharomyces cerevisiae by octanoic acid. J Gen Microbiol. (1991) 137:64551. doi: 10.1099/00221287-137-3-645

57. Sun CQ, O'Connor CJ, Turner SJ, Lewis GD, Stanley RA, Roberton AM. The effect of $\mathrm{pH}$ on the inhibition of bacterial growth by physiological concentrations of butyric acid: implications for neonates fed on suckled milk. Chem Biol Interact. (1998) 113:117-31. doi: 10.1016/S0009-2797(98)00025-8

58. Projan SJ, Brown-Skrobot S, Schlievert PM, Vandenesch F, Novick RP. Glycerol monolaurate inhibits the production of $\beta$ lactamase, toxic shock syndrome toxin-1, and other staphylococcal exoproteins by interfering with signal transduction. J Bacteriol. (1994) 176:4204-4209. doi: 10.1128/jb.176.14.4204-4209.1994

59. Ruzin A, Novick RP. Equivalence of lauric acid and glycerol monolaurate as inhibitors of signal transduction in Staphylococcus aureus. J Bacteriol. (2000) 182:2668-71. doi: 10.1128/JB.182.9.2668-2671.2000

60. Heerklotz H. Interactions of surfactants with lipid membranes. Q Rev Biophys. (2008) 41:205-64. doi: 10.1017/S0033583508004721

61. Batovska DI, Todorova IT, Tsvetkova I V., Najdenski HM. Antibacterial study of the medium chain fatty acids and their 1-monoglycerides: individual effects and synergistic relationships. Polish J Microbiol. (2009) 58:43-7.

62. Kovanda L, Zhang W, Wei X, Luo J, Wu X, Atwill ER, et al. In vitro antimicrobial activities of organic acids. Molecules. (2019) 1-14.

63. Bach AC, Babayan K. Medium-chain triglycerides: an update. Am J Clin Nutr. (1982) 36:950-62. doi: 10.1093/ajcn/36.5.950

64. Sauberan JB, Bradley JS. Antimicrobial agents. Princ Pract Pediatr Infect Dis. (2018) 2:1499-531. doi: 10.1016/B978-0-323-40181-4.00292-9

65. Nguyen DH, Kim IH. Protected organic acids improved growth performance, nutrient digestibility, and decreased gas emission in broilers. Animals. (2020) 10:0-10. doi: 10.3390/ani10030416

66. Khan SH, Iqbal J. Recent advances in the role of organic acids in poultry nutrition. J Appl Anim Res. (2016) 44:359369. doi: $10.1080 / 09712119.2015 .1079527$

67. Dittoe DK, Ricke SC, Kiess AS. Organic acids and potential for modifying the avian gastrointestinal tract and reducing pathogens and disease. Front Vet Sci. (2018) 5:1-12. doi: 10.3389/fvets.2018. 00216 
68. Gutierrez Del Alamo A, De Los Mozos J, Van Dam JTP, Perez de Ayala P. "The use of short and medium chain fatty acids as an alternative to antibiotic growth promoters in broilers infected with malabsorption syndrome," in 16th Eur Symp Poult Nutr. (2006) 317-320. Available online at: https://www.cabi.org/Uploads/animal-science/worldspoultry-science-association/WPSA-france-2007/47.pdf

69. Moquet PCA, Onrust L, Van Immerseel F, Ducatelle R, Hendriks WH, Kwakkel RP. Importance of release location on the mode of action of butyrate derivatives in the avian gastrointestinal tract. Worlds Poult Sci J. (2016) 72:61-80. doi: 10.1017/S004393391500269X

70. Hankel J, Popp J, Meemken D, Zeiger K, Beyerbach M, Taube V, et al. Influence of lauric acid on the susceptibility of chickens to an experimental Campylobacter jejuni colonisation. PLoS One. (2018) 13:122. doi: 10.1371/journal.pone.0204483

71. Wang L, Johnson EA. Inhibition of Listeria monocytogenes by fatty acids and monoglycerides. Appl Environ Microbiol. (1992) 58:6249. doi: 10.1128/aem.58.2.624-629.1992

72. Yang WY, Lee $\mathrm{Y}, \mathrm{Lu} \mathrm{H}$, Chou CH, Wang C. Analysis of gut microbiota and the effect of lauric acid against necrotic enteritis in Clostridium perfringens and Eimeria side-by-side challenge model. PLoS ONE. (2019) 14:1-22. doi: 10.1371/journal.pone.0205784

73. Kabara JJ, Swieczkowski DM, Conley AJ, Truant JP. Fatty acids and derivatives as antimicrobial agents. Antimicrob Agents Chemother. (1972) 2:23-8. doi: 10.1128/AAC.2.1.23

74. Namkung H, Yu H, Gong J, Leeson S. Antimicrobial activity of butyrate glycerides toward salmonella typhimurium and clostridium perfringens. Poult Sci. (2011) 90:2217-22. doi: 10.3382/ps.2011-01498

75. Bergsson G, Steingrimsson O, Thormar H. Bactericidal effects of fatty acids \& monoglycerides on Helicobacter pylori. Int J Antimicrob Agents. (2002) 20:258-62. doi: 10.1016/S0924-8579(02)00205-4

76. Van Immerseel F, Fievez V, De Buck J, Pasmans F, Martel A, Haesebrouck F, et al. Microencapsulated short-chain fatty acids in feed modify colonization and invasion early after infection with Salmonella enteritidis in young chickens. Poult Sci. (2004) 83:69-74. doi: 10.1093/ps/83.1.69

77. Zentek J, Buchheit-Renko S, Ferrara F, Vahjen W, Van Kessel AG, Pieper R. Nutritional and physiological role of medium-chain triglycerides and medium-chain fatty acids in piglets. Anim Health Res Rev. (2011) 12:8393. doi: $10.1017 /$ S1466252311000089

78. Krogdahl A. Digestion and absorption of lipids in poultry. J Nutr. (1985) 115:675-85. doi: 10.1093/jn/115.5.675

79. Bedford A, Gong J. Implications of butyrate and its derivatives for gut health and animal production. Anim Nutr. (2018) 4:151-9. doi: 10.1016/j.aninu.2017.08.010

80. Yoon BK, Jackman JA, Valle-González ER, Cho NJ. Antibacterial free fatty acids and monoglycerides: biological activities, experimental testing, and therapeutic applications. Int J Mol Sci. (2018) 19:1114. doi: 10.3390/ijms19041114

81. Kabara JJ, Vrable R, Lie Ken Jie MSF. Antimicrobial lipids: natural and synthetic fatty acids and monoglycerides. Lipids. (1977) 12:7539. doi: 10.1007/BF02570908

82. Hyldgaard M, Sutherland DS, Sundh M, Mygind T, Meyer RL. Antimicrobial mechanism of monocaprylate. Appl Environ Microbiol. (2012) 78:295765. doi: 10.1128/AEM.07224-11

83. Timbermont L. A Contribution to the Pathogenesis and Treatment of Clostridium Perfringens-Associated Necrotic Enteritis in Broilers. $\mathrm{PhD}$ Diss. (2009).

84. Bergsson G, Arnfinnsson J, Steingrímsson Ó, Thormar H. Killing of grampositive cocci by fatty acids and monoglycerides. Apmis. (2001) 109:6708. doi: 10.1034/j.1600-0463.2001.d01-131.x

85. Yoon BK, Jackman JA, Kim MC, Sut TN, Cho NJ. Correlating membrane morphological responses with micellar aggregation behavior of capric acid and monocaprin. Langmuir. (2017) 33:2750-9. doi: 10.1021/acs.langmuir.6b03944

86. Fortuoso BF, dos Reis JH, Gebert RR, Barreta M, Griss LG, Casagrande RA, et al. Glycerol monolaurate in the diet of broiler chickens replacing conventional antimicrobials: impact on health, performance and meat quality. Microb Pathog. (2019) 129:161-7. doi: 10.1016/j.micpath.2019.02.005
87. Van Immerseel F, De Buck J, Boyen F, Bohez L, Pasmans F, Volf J, et al. Medium-chain fatty acids decrease colonization and invasion through hilA suppression shortly after infection of chickens with Salmonella enterica serovar enteritidis. Appl Environ Microbiol. (2004) 70:35827. doi: 10.1128/AEM.70.6.3582-3587.2004

88. Hermans D, Martel A, Garmyn A, Verlinden M, Heyndrickx M, Gantois I, et al. Application of medium-chain fatty acids in drinking water increases Campylobacter jejuni colonization threshold in broiler chicks. Poult Sci. (2012) 91:1733-8. doi: 10.3382/ps.2011-02106

89. Andrews JM. Determination of minimum inhibitory concentrations. $J$ Antimicrob Chemother. (2001) 48:5-16. doi: 10.1093/jac/48.suppl_1.5

90. Kien CL, Blauwiekel R, Bunn JY, Jetton TL, Frankel WL, Holst JJ. Cecal infusion of butyrate increases intestinal cell proliferation in piglets. J Nutr. (2007) 137:916-22. doi: 10.1093/jn/137.4.916

91. Scheppach W. Effects of short chain fatty acids on gut morphology and function. Gut. (1994) 35:S35-8. doi: 10.1136/gut.35.1_Suppl.S35

92. Guilloteau P, Martin L, Eeckhaut V, Ducatelle R, Zabielski R, Van Immerseel F. From the gut to the peripheral tissues: the multiple effects of butyrate. Nutr Res Rev. (2010) 23:366-84. doi: 10.1017/S0954422410000247

93. Peng L, Li ZR, Green RS, Holzman IR, Lin J. Butyrate enhances the intestinal barrier by facilitating tight junction assembly via activation of AMP-activated protein kinase in Caco-2 cell monolayers. J Nutr. (2009) 139:1619-25. doi: 10.3945/jn.109.104638

94. Dauksiene A, Ruzauskas M, Gruzauskas R, Zavistanaviciute P, Starkute $\mathrm{V}$, Lele V, et al. A comparison study of the caecum microbial profiles, productivity and production quality of broiler chickens fed supplements based on medium chain fatty and organic acids. Animals. (2021) 11:122. doi: $10.3390 /$ ani1 1030610

95. Abdelli N, Pérez JF, Vilarrasa E, Luna IC, Melo-Duran D, D'angelo M, et al. Targeted-release organic acids and essential oils improve performance and digestive function in broilers under a necrotic enteritis challenge. Animals. (2020) 10:20259. doi: 10.3390/ani10020259

96. Kumar A, Toghyani M, Kheravii SK, Pineda L, Han Y, Swick RA, et al. Potential of blended organic acids to improve performance and health of broilers infected with necrotic enteritis. Anim Nutr. (2021) 7:4409. doi: 10.1016/j.aninu.2020.11.006

97. Kumar A, Kheravii SK, Li L, Wu S. Monoglyceride Blend Reduces Mortality, Improves Nutrient Digestibility, and Intestinal Health in Broilers Subjected to Clinical Necrotic Enteritis Challenge. Animals. (2021) 11:19. doi: 10.3390/ani11051432

98. Onrust L, Van Driessche K, Ducatelle R, Schwarzer K, Haesebrouck F, Van Immerseel F. Valeric acid glyceride esters in feed promote broiler performance and reduce the incidence of necrotic enteritis. Poult Sci. (2018) 97:2303-11. doi: 10.3382/ps/pey085

99. Whelan RA, Doranalli K, Rinttilä T, Vienola K, Jurgens G, Apajalahti J. The impact of Bacillus subtilis DSM 32315 on the pathology, performance, and intestinal microbiome of broiler chickens in a necrotic enteritis challenge. Poult Sci. (2019) 98:3450-63. doi: 10.3382/ps/pey500

100. Xu S, Lin Y, Zeng D, Zhou M, Zeng Y, Wang H, et al. Bacillus licheniformis normalize the ileum microbiota of chickens infected with necrotic enteritis. Sci Rep. (2018) 8:1-10. doi: 10.1038/s41598-018-20059-z

101. Wang L, Lilburn M, Yu Z. Intestinal microbiota of broiler chickens as affected by litter management regimens. Front Microbiol. (2016) 7:112. doi: $10.3389 /$ fmicb. 2016.00593

102. Wei S, Gutek A, Lilburn M, Yu Z. Abundance of pathogens in the gut and litter of broiler chickens as affected by bacitracin and litter management. Vet Microbiol. (2013) 166:595-601. doi: 10.1016/j.vetmic.2013.06.006

103. Antonissen G, Eeckhaut V, Van Driessche K, Onrust L, Haesebrouck F, Ducatelle R, et al. Microbial shifts associated with necrotic enteritis. Avian Pathol. (2016) 45:308-312. doi: 10.1080/03079457.2016.1152625

104. Ballou AL, Ali RA, Mendoza MA, Ellis JC, Hassan HM, Croom WJ, et al. Development of the chick microbiome: how early exposure influences future microbial diversity. Front Vet Sci. (2016) 3:1-12. doi: 10.3389/fvets.2016.00002

105. Wei S, Morrison M, Yu Z. Bacterial census of poultry intestinal microbiome. Poult Sci. (2013) 92:671-83. doi: 10.3382/ps.2012-02822

106. Stanley D, Wu SB, Rodgers N, Swick RA, Moore RJ. Differential responses of cecal microbiota to fishmeal, eimeria and clostridium perfringens 
in a necrotic enteritis challenge model in chickens. PLoS ONE. (2014) 9:e104739. doi: 10.1371/journal.pone.0104739

107. Yu Q, Lepp D, Gohari IM, Wu T, Zhou H, Yin X, et al. The Agrlike quorum sensing system is required for pathogenesis of necrotic enteritis caused by Clostridium perfringens in poultry. Infect Immun. (2017) 85:16. doi: 10.1128/IAI.00975-16

108. Gray B, Hall P, Gresham H. Targeting agr- and agr-like quorum sensing systems for development of common therapeutics to treat multiple gram-positive bacterial infections. Sensors. (2013) 13:51305166. doi: 10.3390/s130405130

109. Thompson JA, Oliveira RA, Djukovic A, Ubeda C, Xavier KB. Manipulation of the quorum sensing signal AI-2 affects the antibiotic-treated gut microbiota. Cell Rep. (2015) 10:1861-1871. doi: 10.1016/j.celrep.2015.02.049

110. Silva YP, Bernardi A, Frozza RL. The role of short-chain fatty acids from gut microbiota in gut-brain communication. Front Endocrinol. (2020) 11:114. doi: $10.3389 /$ fendo. 2020.00025

111. Venegas DP, De La Fuente MK, Landskron G, González MJ, Quera R, Dijkstra G, et al. Short chain fatty acids (SCFAs)mediated gut epithelial and immune regulation and its relevance for inflammatory bowel diseases. Front Immunol. (2019) 10:1486. doi: 10.3389/fimmu.2019.01486

112. Ríos-Covián D, Ruas-Madiedo P, Margolles A, Gueimonde M, De los Reyes-Gavilán CG, Salazar N. Intestinal short chain fatty acids and their link with diet and human health. Front Microbiol. (2016) 7:19. doi: 10.3389/fmicb.2016.00185

113. Puddu A, Sanguineti R, Montecucco F, Viviani GL. Evidence for the gut microbiota short-chain fatty acids as key pathophysiological molecules improving diabetes. Mediators Inflamm. (2014) 2014:21. doi: 10.1155/2014/162021

114. Hara T, Kimura I, Inoue D, Ichimura A, Hirasawa A. Free fatty acid receptors and their role in regulation of energy metabolism. Rev Physiol Biochem Pharmacol. (2013) 164:77-116. doi: 10.1007/112_2013_13

115. Oakley BB, Buhr RJ, Ritz CW, Kiepper BH, Berrang ME, Seal BS, et al. Successional changes in the chicken cecal microbiome during 42 days of growth are independent of organic acid feed additives. BMC Vet Res. (2014) 10:1-8. doi: 10.1186/s12917-014-0282-8

116. Bortoluzzi C, Pedroso AA, Mallo JJ, Puyalto M, Kim WK, Applegate TJ. Sodium butyrate improved performance while modulating the cecal microbiota and regulating the expression of intestinal immune-related genes of broiler chickens. Poult Sci. (2017) 96:3981-93. doi: 10.3382/ps/pex218

117. Zhou Z, Nie K, Huang Q, Li K, Sun Y, Zhou R, et al. Changes of cecal microflora in chickens following Eimeria tenella challenge and regulating effect of coated sodium butyrate. Exp Parasitol. (2017) 177:7381. doi: 10.1016/j.exppara.2017.04.007

118. Papamandjaris AA, Macdougall DE, Jones PJH. Medium chain fatty acid metabolism and energy expenditure: obesity treatment implications. Life Sci. (1998) 62:1203-15. doi: 10.1016/S0024-3205(97)01143-0

119. Svoboda E. A gut feeling. Nature. (2021) 595:S545. doi: 10.1038/d41586-021-01837-8

120. Altindis E, Cai W, Sakaguchi M, Zhang F, GuoXiao W, Liu F, et al. Viral insulin-like peptides activate human insulin and IGF-1 receptor signaling: a paradigm shift for host-microbe interactions. Proc Natl Acad Sci U S A. (2018) 115:2461-2466. doi: 10.1073/pnas.1721117115

Conflict of Interest: Commercial companies employed several of the authors of this paper, at the time of the writing of this paper, as follows: L-MG-O employed by Alura Animal Health and Nutrition, VY-M by Okuo, A. Ballou by Iluma Alliance, and M. Parini by Silo. Alura Animal Health and Nutrition is a company that sells therapeutic and prophylactic antibiotics and anticoccidials as well as natural health alternatives including SCFA and MCFA for animal husbandry. Okuo sells food safety products for processing plants. Iluma is involved in formulation services, sale of vitamin and mineral premixes as well as health products for animal agriculture. Silo sells vitamins, amino acids, fiber compounds, SCFA and MCFA. None of these companies exclusively sells SCFA and MCFA.

The remaining authors declare that the research was conducted in the absence of any commercial or financial relationships that could be construed as a potential conflict of interest.

Publisher's Note: All claims expressed in this article are solely those of the authors and do not necessarily represent those of their affiliated organizations, or those of the publisher, the editors and the reviewers. Any product that may be evaluated in this article, or claim that may be made by its manufacturer, is not guaranteed or endorsed by the publisher.

Copyright (c) 2021 Gomez-Osorio, Yepes-Medina, Ballou, Parini and Angel. This is an open-access article distributed under the terms of the Creative Commons Attribution License (CC BY). The use, distribution or reproduction in other forums is permitted, provided the original author(s) and the copyright owner(s) are credited and that the original publication in this journal is cited, in accordance with accepted academic practice. No use, distribution or reproduction is permitted which does not comply with these terms. 